\title{
Correlations between Positron Annihilation Parameters and Macroscopic Properties in Copolymers Belonging to Elastomers Group
}

\author{
K. Krzemień, J. KansY* \\ Institute of Material Science, University of Silesia \\ Bankowa 12, 40-007 Katowice, Poland
}

\begin{abstract}
The positron annihilation lifetime spectroscopy was used to study correlations between positron annihilation parameters and macroscopic properties in two kinds of polymers from elastomers group. Two kinds of material were investigated: three samples of ethylene octane copolymers (commercial name engage) of different densities and six samples of polybutylene terephtalate-polyether glycol copolymers (hytrel) having different densities. A correlation between intensity of ortho-positronium component and the density $(d)$ of samples was observed for both kinds of material. From the ortho-positronium pick-off lifetime the mean radii $(R)$ of free volume centers were determined. A good linear correlation between $R$ and $d$ was found.
\end{abstract}

PACS numbers: 78.70.Bj, 71.60.+z, 61.41.+e

\section{Introduction}

The positron annihilation lifetime spectroscopy (PALS) is one of the most important methods that provides unique information about the properties of subnanometer-size local free volumes in polymers. In polymers a part of positrons injected from radioactive source may form positronium (Ps), a bound state of a positron and an electron. Ps has two spin states, a short-lived singlet state ( ara-Ps, $p$-Ps) with a lifetime of about $125 \mathrm{ps}$ in vacuum, and a long-lived triplet state (ortho-Ps, o-Ps) with a lifetime of about $142 \mathrm{~ns}$ in vacuum. However, the lifetime of $o$-Ps (in polymers) is shortened to a few nanoseconds because Ps can be trapped into the free volumes, and the positron of $o$-Ps can annihilate with an electron from the surrounding molecules. The positron annihilation lifetime spectrum

*corresponding author; e-mail: kansy@us.edu.pl 
of polymers is deconvoluted usually into three components, attributed to annihilation of $p$-Ps, free positron and $o$-Ps, respectively. The most useful information supplies the third component since the lifetime parameter $\left(\tau_{3}\right)$ of this component is related to the mean size of the free volume holes in polymer $[1,2]$. Intensity of this component $\left(I_{3}\right)$ is often considered to be proportional to the total free volume in sample. However, this statement is questionable because of other factors like irradiation of material [3-7], crystallinity [8-11] of polymer, the presence of electron/positron scavengers [12], the degree of cross-links and the condition of polymerization [13].

The purpose of this work is to investigate relations between some physical properties (e.g. crystallinity, density, hardness) of chosen polymers from elastomers group and the positron annihilation parameters, i.e. $I_{3}$ and $\tau_{3}$.

\section{Experimental}

\subsection{Materials}

The materials under investigation were two kinds of copolymers supplied by DuPont Dow Elastomers. The first are three different samples of ethylene octane copolymer (commercial name - engage). The general formula of engage type polymer is given by

$$
\left.-\mathrm{CH}_{2}-\mathrm{CH}_{2}\right]_{\mathrm{n}}\left[\mathrm{CH}_{2}-\mathrm{CH}-\left(\mathrm{CH}_{2}\right)_{5}-\mathrm{CH}_{3}\right]_{\mathrm{m}}
$$

The second kind were six samples of hytrel — which is a copolymer, consisting of a hard (crystalline) segment of polybutylene terephtalate and a soft amorphous segment of polyether glycol. The general formula of hytrel type polymer is given by

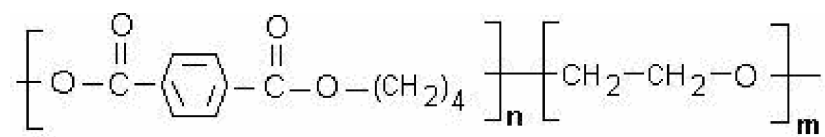

The typical and the most important properties of engage and hytrel copolymers are shown in Tables I and II.

TABLE I

Some properties of engage polymers (according to manufacturer DuPont).

\begin{tabular}{l|c|c|c|c}
\hline \hline & $\begin{array}{c}\text { Engage } \\
8150\end{array}$ & $\begin{array}{c}\text { Engage } \\
8200\end{array}$ & $\begin{array}{c}\text { Engage } \\
8400\end{array}$ & $\begin{array}{c}\text { Engage } \\
8003\end{array}$ \\
\hline Density $\left[\mathrm{g} / \mathrm{cm}^{3}\right]$ & 0.868 & 0.870 & 0.870 & 0.885 \\
Elongation at break [\%] & 780 & $>1000$ & $>1000$ & 670 \\
Durometer hardness [Shore A] & 75 & 75 & 72 & 86 \\
Glass transition temperature $\left[{ }^{\circ} \mathrm{C}\right]$ & -56 & -56 & -57 & -86
\end{tabular}


TABLE II

Some properties of hytrel polymers (according to manufacturer DuPont).

\begin{tabular}{l|c|c|c|c|c|c}
\hline \hline & Hytrel & Hytrel & Hytrel & Hytrel & Hytrel & Hytrel \\
& 4556 & 4056 & 5556 & 6356 & 7246 & 8238 \\
\hline Density $\left[\mathrm{g} / \mathrm{cm}^{3}\right.$ ] & 1.14 & 1.17 & 1.2 & 1.22 & 1.25 & 1.28 \\
Elongation at break [\%] & 600 & 550 & 500 & 420 & 360 & 350 \\
Durometer hardness [Shore A] & 45 & 40 & 55 & 63 & 72 & 82 \\
Flexural modules [MPa] & 27 & 44 & 110 & 150 & 207 & 255
\end{tabular}

\subsection{PALS Experiment}

The PALS experiment was carried out at room temperature using a fast-fast coincidence system with a time resolution of 219 ps (FWHM) monitored by using ${ }^{60} \mathrm{Co}$ source. Two identical samples were sandwiched between $5 \mu \mathrm{Ci}$ sodium chloride radioactive source ${ }^{22} \mathrm{Na}$ which was prepared by the evaporate ${ }^{22} \mathrm{NaCl}$ solution on a kapton foil. For each samples a series of 5 PALS spectra were collected in situ. Each lifetime spectrum contained ca. $2.5 \times 10^{6}$ counts. In this way, the total statistics of the spectra making up a series was not less than $10^{7}$ counts.

\subsection{Computer analysis}

The computer analysis was performed with the LT 9 program [14]. Each spectrum was resolved into three exponential components, of lifetimes parameters $\tau_{i}$ and intensities $I_{i}(i=1 \ldots 3)$. Each series of spectra related to a sample of a given density was analyzed simultaneously. The model parameters $\tau_{i}$, and $I_{i}$ were assumed common to all the spectra making up the series. During the analysis the contribution from the annihilation in the source $(I=11.2 \%, \tau=0.386 \mathrm{~ns})$ and instrumental resolution were taken into account.

\section{Results and discussion}

Figure 1 shows $I_{3}$ as a function of density $(d)$ of investigated polymers. The quantities correlate well on straight lines. According to manufacturer [15]

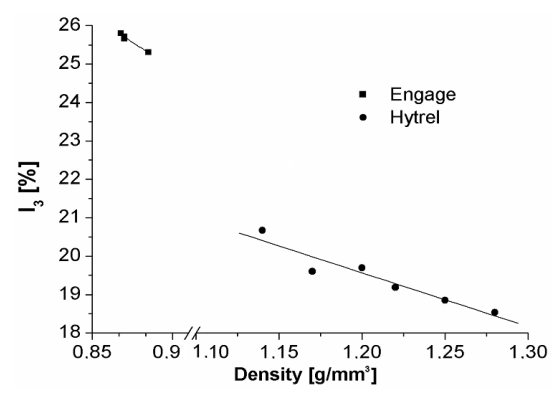

Fig. 1. The variation of intensity $I_{3}$ as a function of density. 


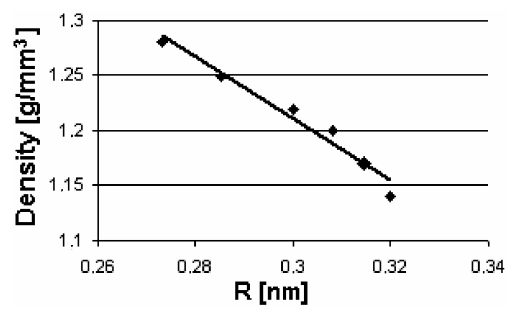

Fig. 2. The variation of $R$ as a function of density in hytrel copolymer.

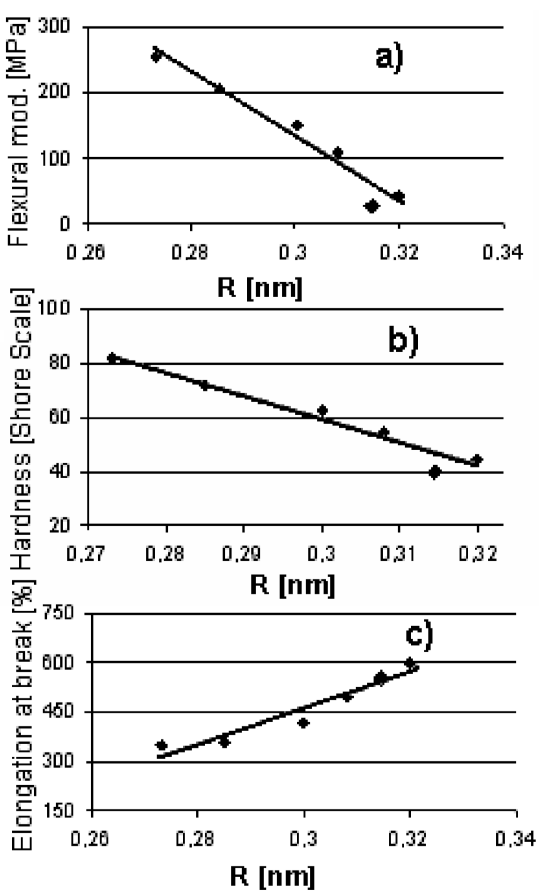

Fig. 3. The variation of some properties (flexural module (a), hardness (b), elongation at break (c)) as a function of $R$ in hytrel copolymer.

in these type of semicrystalline copolymers, the density is proportional to their crystallinity. Therefore, the observed correlation can be considered as a correlation between the crystallinity of samples and $I_{3}$. The efficiency of $o$-Ps formation decreases with the elevation of crystallinity (with decrease in amount of amorphous phase in sample). Because this dependence is linear, it suggests that $o$-Ps is formed in amorphous phase solely. This is in agreement with results observed for poly(acryl ether ethercetone) (PEEK) [9], semicrystalline polyamides [10], and in disagreement with the result of investigations for semicrystalline polyethylene [11], which supports an opposite thesis. From the determined values of $\tau_{3}$ we calcu- 
lated mean radii $(R)$ of free volume cavities for each sample from the Tao-Eldrup formula $[1,2]$ :

$$
\tau_{o-\mathrm{Ps}}=0.5\left[1-\frac{R}{1.65 \AA}+\frac{1}{2 \pi} \sin \left(\frac{2 \pi R}{1.65 \AA}\right)\right]^{-1} \mathrm{~ns} .
$$

The influence of density (crystallinity) of samples on $R$ is also observed (Fig. 2). It is seen that the dependence between $d$ and $R$ is a very good linear correlation. Assuming (as it was suggested by our results) that $o$-Ps is formed in amorphous phase exclusively, one can conclude that higher crystallinity of sample is accompanied by lower size of free volume holes in amorphous phase. Similarly, $R$ correlates with other macroscopic characteristics (Tables I and II) such as flexural module, elongation at break, and hardness of investigated samples (Fig. 3), which confirms strong influence of free volume on physical properties of polymers.

\section{Conclusions}

PALS is a sensitive method to observe the microstructure of polymers caused by different ratio of amorphous and crystalline phases. Linear correlation between density of sample and intensity of $o$-Ps component as well as mean size of free volume holes suggests that positronium is formed in amorphous phase solely. For the investigated polymers strong influence of the mean size of free volume holes on the macroscopic properties (density, elongation at break, hardness or flexural modules) is observed.

\section{References}

[1] S.T. Tao, J. Chem. Phys. 56, 5499 (1972).

[2] N. Eldrup, D. Lightbody, J.N. Sherwood, Chem. Phys. 63, 51 (1981).

[3] C.L. Wang, B. Wang, S.Q. Li, S.J. Wang, J. Phys., Condens. Matter 5, 7515 (1993).

[4] S.J. Wang, C.L. Wang, B. Wang, J. Radioanal. Nucl. Chem. 210, 407 (1996).

[5] T. Suzuki, Y. Ito, K. Kondo, E. Hamada, Y. Ito, Radiat. Phys. Chem. 58, 485 (2000).

[6] T. Suzuki, Y. Ito, K. Kondo, E. Hamada, Z.Q. Chen, Y. Ito, Radiat. Phys. Chem. 60, 535 (2001).

[7] R.S. Yu, T. Suzuki, N. Djourelov, K. Kondo, Y. Ito, V.P. Shantarovich, Chem. Phys. 313, 63 (2005).

[8] Y. Ito, T. Suzuki, Radiat. Phys. Chem. 66, 343 (2003).

[9] H. Naganishi, J.C. Jean, E.G. Smith, T.C. Sandrecki, J. Polym. Sci. Part B, Polym. Phys. 27, 1419 (1989).

[10] G. Dlubek, M. Stolp, Ch. Nagle, H.N. Fretwell, M.A. Alam, H.J. Radusch, J. Phys. 10, 10443 (1998).

[11] G. Dlubek, J. Stejny, T.H. Lüpke, D. Bamford, K. Petters, C.H. Hübner, M.A. Alam, M.J. Hill, J. Polym. Sci. B 40, 65 (2002). 
[12] V.P. Shantarovich, T. Suzuki, C. He, V.W. Gustov, Radiat. Phys. Chem. 67, 15 (2003).

[13] T. Suzuki, T. Hayashi, Y. Ito, Mater. Res. Innovation 4, 273 (2001).

[14] J. Kansy, Nucl. Instrum. Methods. Phys. Res. A 374, 235 (1996).

[15] Engage, polyolefin elastomer, Produkt Information, DuPont Dow Elastomers S.A., Geneva, Switzerland. 